\title{
Adaptation, Development Assistance and Planning: Challenges and Opportunities
}

\author{
Shardul Agrawala*
}

\section{Introduction}

There is no doubt that climate is closely intertwined with economic development. Climate is a resource in itself and it also mediates the productivity of several other critical resources, including food and fibre, forests, fisheries and water resources. Climate can also be a hazard. Natural fluctuations in climate such as those related to El Niño cause widespread disruptions in society's ability to harness resources and even survive (Agrawala and Cane 2002). At the same time, human development choices are having a demonstrable impact on the state of the climate system. Among the most significant is global climate change through the emission of greenhouse gases. Not only have development choices and pathways resulted in the emissions of greenhouse gases in the atmosphere, but how development occurs will also determine the ability of societies to adapt to the potential impacts of climate change which will be primarily manifested through increases in temperature, changes in rainfall and sea level rise (see Pachauri, this Bulletin).

Adaptation refers to adjustments in ecological, social, or economic systems in response to actual or expected climatic stimuli and their effects or impacts (IPCC 2001). Different kinds of adaptation are possible and are described in more detail by Huq and Reid (this Bulletin). That adaptation responses could at least partially offset some of the potential impacts of climate change has been recognised in all assessments of climate change, dating back to the 1990 First Assessment Report of the Intergovernmental Panel on Climate Change (IPCC). Nevertheless, adaptation received only limited attention in both the IPCC First and Second Assessment Reports. This was due to several reasons. First, there are significant uncertainties with regard to the projections of climate change impacts, while the understanding of the processes and mechanisms by which adaptation takes place is rather limited. Second, adaptation frequently occurs within a suite of responses that may be linked to a broader range of societal concerns, many of which may have fallen outside of the purview of the climate change only focus on climate assessments. Finally, much of the policy debate, until the negotiation of the Kyoto Protocol, was driven almost exclusively by the need for greenhouse gas mitigation and some contend that too much emphasis on adaptation may have distracted from the need for mitigation commitments (Kates 1997).

Several developments over the past five years or so have progressively raised the status of adaptation to a point where it is increasingly recognised as an equal and complementary response to greenhouse gas mitigation. These developments include the establishment of the Special Climate Change Fund (SCCF) and the Least Developed Countries (LDC) Fund under the auspices of the Climate Convention and a (yet to be operationalised) Adaptation Fund under the Kyoto Protocol (Dessai and Schipper 2003; Huq and Reid, this Bulletin). From a scientific perspective meanwhile, adaptation received an added impetus with the publication of the IPCC Third Assessment Report, which provides a typology of adaptation responses and establishes linkages with sustainable development.

\section{The demand pull}

In addition to the supply push from the climate change to the development community, there are also early signs of a demand pull from the opposite direction. In particular, donor agencies as well as sectoral planners in several national governments are increasingly coming to terms with the issue of how to incorporate projected impacts of climate change within their core development activity. 
Prominent among such efforts are scoping reports by the World Bank, Gesellschaft für Technische Zusammenarbeit (GTZ) and the Norwegian Agency for Development Cooperation (NORAD), on linkages between their development assistance portfolios and climate change adaptation (Burton and van Aalst 1999; Klein 2001; Eriksen and Næss 2003). There have also been two in-depth regional/national analyses funded by the World Bank on the potential responses to climate change within a regional/national context in the Pacific Region and Bangladesh respectively (World Bank 2000a; World Bank 2000b). More recently, ten multilateral and bilateral development agencies led by the World Bank affirmed the central importance of climate change impacts and adaptation to the achievement of their core mandate on poverty alleviation (Sperling, Multi Agency Report 2003).

Despite this flurry of interest in climate change adaptation from certain parts of the development community, there is also a fair degree of scepticism in other quarters. How does a global concern like climate change, aspects of which might manifest itself decades to centuries in the future, compare with more immediate, local/regional priorities for development, such as poverty, food security, sanitation and public health? How can one assess the exposure of development portfolios to potential risks of climate change? Further, given that coping with the impacts of weather extremes is already an integral part of ongoing development activities ranging from famine early warning and flood plain management, would climate change really require anything different in operational terms?

These questions have unfortunately not yet received as much attention as they merit from the climate change community which has traditionally been more focused on issues such as adaptation financing within the context of the multilateral climate change regime, than with having a substantive dialogue with the core of the development community. There are however signs of change and the present issue of the Bulletin intended for the development audience, is a step in this direction.

\section{Some insights from recent OECD work}

The Organisation for Economic Cooperation and Development (OECD), an intergovernmental body with a membership of 30 industrialised countries, has traditionally focused its climate change work on economic and policy analyses related to greenhouse gas mitigation. OECD countries however, are also the principal providers of development assistance and the organisation is home to the Development Assistance Community (DAC), which serves as the coordinating forum for the donor community. It is within this context that the OECD Environment and Development Cooperation directorates initiated a joint project on Development and Climate Change in 2002. The main objective of this project is to explore possible synergies and trade-offs in "mainstreaming" responses to climate change within development assistance policies of OECD donors, as well as national and sectoral policies and projects of the recipient countries. Six case studies were conducted in Bangladesh, Egypt, Fiji, Nepal, Tanzania and Uruguay, which have all now been completed (OECD 2003a-d; OECD 2004a-b, available at: www.oecd.org/env/cc).

Each of the case studies followed a three-tier framework (Agrawala and Berg 2002) that included:

1. A country-level overview of principal climate change impacts and vulnerabilities.

2. Analyses of national plans and development assistance portfolios that bear upon vulnerable sectors and regions.

3. In-depth analyses at a regional/sectoral level of how climate change adaptation responses can be mainstreamed in particular development policies and projects.

The in-depth analyses have addressed a range of issues where climate change adaptation is very closely intertwined with development, including water resource management on the Nile, coastal mangroves in Fiji and the Bangladesh Sundarbans, glacier retreat and water resource management in Nepal, economic development and natural resource management on Mount Kilimanjaro and coastal zones management in Egypt and Uruguay.

Several findings have emerged from this body of work that bear upon the challenge of mainstreaming adaptation within a development planning and assistance context. An analysis of the composition of official flows (official development assistance and loans) to the six case study countries indicates that a significant portion is in sectors potentially affected by climatic risks, including by climate change. Over a three-year period from 1998 
to 2000 the estimates range from between US $\$ 1-2$ billion for Egypt and Bangladesh to several hundred million dollars for countries such as Nepal and Tanzania. Expressed as a percentage of total national official flows, estimates range from as high as 50-65 per cent in Nepal to 12-26 per cent in Tanzania. While any classification based on sectors suffers from over-simplification, it is evident that consideration of climatic risks (including climate change) might often be central to development investments and projects. The absolute magnitude of official flows in sectors potentially affected by climatic risks meanwhile is considerably higher than funding amounts committed to financing adaptation as part of the climate change regime. Therefore, over the long term, there appears to be far greater potential to mainstream adaptation within core development activity, compared to the financing of action on adaptation initiated from within the climate regime.

Another finding from the OECD case studies is that there is growing evidence that long-term climate trends and climate change are already having a significant impact on development. This is particularly the case for Nepal, where significant glacier retreat has been observed, along with higher rates of temperature increase in the High Himalayas. This retreat has also contributed to the expansion of several high altitude glacial lakes. Glacier retreat contributes to a reduction in dry season river flows and can have direct impacts on water availability and hydropower generation. Expansion of glacial lakes meanwhile, increases the risks of "glacial lake outburst floods" (GLOFs), which can have devastating impacts several hundred kilometres downstream in terms of loss of life, livelihoods and development infrastructure (OECD 2003a). One GLOF event (in 1985) in Nepal destroyed a World Bank funded hydropower facility, shortly after it was commissioned. Long-term climatic trends are having an entirely different impact on Mount Kilimanjaro in Tanzania. A trend towards warmer and dryer conditions has considerably increased fire risks and has contributed to a significant loss of the sub-alpine cloud forest on the Kilimanjaro. Not only does it impact the viability of a critical ecosystem and the livelihoods dependent upon it, but the loss of the cloud belt has also reduced the ability of the ecosystem to trap vast quantities of water from fog, leading to significant reduction in local water availability (OECD 2003d).
It is therefore clear that development activities at several levels, from water resource infrastructure to rural livelihoods, might need to adapt to the potential implications of medium- to long-term changes in climate and not just short-term weather extremes and climate variability.

Do development plans and projects pay sufficient attention to climatic risks and climate change in particular? An analysis of national development plans, poverty reduction strategy papers (PRSPs), sectoral development strategies, as well as donor Country Assistance Strategies and project design documents and evaluations for the six case study countries indicates that in general such documents pay negligible attention to climate change and often only limited attention to current weather and climatic risks. Some exceptions include the Interim PRSP of Bangladesh which recognises direct links between poverty and vulnerability to natural hazards and the fact that such vulnerability might increase under global climate change. Also, considerable progress has been made to sensitise "line" ministries and departments to the potential risks of climate change in Bangladesh and Fiji. Bangladesh for example has formulated a National Water Policy in 1999 and a subsequent National Water Management Plan in 2001, which recognise climate change as one of the factors determining Bangladesh's future water supply and demand. Fiji, meanwhile, is actively engaged in consultations within the Pacific Island countries where no-regrets adaptation and mainstreaming have received high-level political endorsement.

From the bottomup however, policy coherence between climate and development remains a major concern. For example, in Fiji, coastal mangroves, which provide natural protection against sea level rise and storm surges and are therefore good noregrets adaptation, face continued destruction. This is in part because they are valued at only a fraction of official estimates in making decisions with regard to conversion for development purposes (OECD 2003c). In Bangladesh meanwhile, deliberate salt water inundation to boost shrimp production already increases salinity levels and poses risks to the Sundarbans in ways that might be comparable with what may be experienced several decades from now as a result of sea level rise (OECD 2003b). Policy coherence is also a concern in Nepal where efforts are already underway to cope with the effects of glacier retreat and enhancement of glacial lake outburst flooding risks. Some climate change 
impacts, particularly reduction in dry season flows as a result of glacier retreat, may require the construction of dams as an adaptation response, which might be in conflict with other environmental and development priorities (OECD 2003a). In all these cases there is therefore a need for climate experts, sectoral planners and relevant stakeholders to engage in dialogue and to suggest strategies and measures on how best to incorporate adaptation to potential impacts of climate change as part of sectoral and development plans.

\section{Concluding remarks}

There has been considerable evolution in the dialogue between the climate change and the development communities on the issue of adaptation. What may have started with viewpoints akin to climate determinism on the one hand and "why bother?" on the other, is slowly evolving into a more nuanced dialogue on whether and how

\section{Note}

* The views expressed in this article are the author's own and not necessarily those of the OECD or its member governments.

\section{References}

Agrawala, S. and Berg, M., 2002, Development and Climate Change Project-Concept Paper on Scope and Criteria for Case Study Selection', COM/ENV/EPOC/DCD/DAC(2002)1/FINAL, accessed 2002, Paris: OECD

Agrawala, S. and Cane, M.A., 2002, 'Sustainability: lessons from climate change and variability', Columbia Journal of Environmental Law, Vol 27 No 2: 309-21

Burton, I. and van Aalst, M., 1999, 'Come hell or high water - integrating climate change vulnerability and adaptation into Bank work', Environment Department Working Paper 72 , Climate Change Series, Washington, D.C.: The World Bank

Dessai, S. and Schipper, E.L., 2003, 'The Marrakech accords to the Kyoto Protocol: analysis and future prospects', Global Environmental Change 13: 149-53

Eriksen, S. and Næss, L.O., 2003, 'Pro-poor climate adaptation - Norwegian development cooperation and climate change adaptation. An assessment of issues, strategies and potential entry points', CICERO Report 2003: 02, Oslo, Norway adaptation to climate change might need to be incorporated in development efforts. The significance of climate change relative to other contextual factors that confront development will need to be evaluated on a case by case basis. As illustrated by the OECD case studies, there are likely to be a growing number of cases where climate change might be an immediate concern to development activity. In other cases, climate change impacts might only warrant attention over the medium to long term and might not end up becoming immediate priorities for development. There is also a need for further work both at the donor and at the national/sub-national level to develop appropriate tools to screen development projects for exposure to climate risks. Finally, mainstreaming adaptation is not only an issue for the developing world, but also for domestic OECD contexts, a subject which merits further analysis.

IPCC, 2001, 'Adaptation to Climate Change in the Context of Sustainable Development and Equity', in IPCC (eds), Climate Change 2001: Impacts, Adaptation and Vulnerability, Cambridge: Cambridge University Press: 879-12

Kates, R.W., 1997, 'Report on reports: climate change 1995 - impacts, adaptation and mitigation', Environment, Vol 39 No 9: 29-33

Klein, R.J.T., 2001, Adaptation to Climate Change in German Development Assistance - An Inventory of Activities and Opportunities with a special Focus on Africa, Eschborn: Deutsche Gesellschaft für Technische Zusammenarbeit (GTZ)

OECD, 2004a, Development and Climate Change in Egypt: Focus on Coastal Resources and the Nile, COM/ENV/EPOC/DCD/DAC(2004)1/FINAL, Paris: OECD

OECD, 2004b, Development and Climate Change in Uruguay: Focus on Coastal Zones, Agriculture and Forestry, COM/ENV/EPOC/DCD/DAC(2004)2/ FINAL, Paris: OECD

OECD, 2003a, Development and Climate Change in Nepal: Focus on Water Resources and Hydropower, COM/ENV/EPOC/DCD/DAC(2003)1/FINAL, Paris: OECD 
OECD, 2003b, Development and Climate Change in Bangladesh: Focus on Coastal Flooding and the Sundarbans, COM/ENV/EPOC/DCD/DAC(2003)3/ Final, Paris: OECD

OECD, 2003c, Development and Climate Change in Fiji: Focus on Coastal Mangroves, COM/ENV/ EPOC/DCD/DAC(2003)4/Final, Paris: OECD

OECD, 2003d, Development and Climate Change: Focus on Mount Kilimanjaro, COM/ENV/EPOC/ DCD/DAC(2003)5/FINAL, Paris: OECD

Sperling, F. (ed.), 2003, Multi Agency Report, Poverty and Climate Change: Reducing the Vulnerability of the Poor Through Adaptation, inter-agency report by the African Development Bank (AfDB), Asian Development Bank (ADB), Department for
International Development (DFID, UK), Federal Ministry for Economic Cooperation and Development (BMZ, Germany), Ministry of Foreign Affairs - Development Cooperation (DGIS, The Netherlands), Organisation for Economic Cooperation and Development (OECD), United Nations Development Programme (UNDP), United Nations Environment Programme (UNEP) and the World Bank

World Bank, 2000a, Bangladesh: Climate Change and Sustainable Development, Washington, D.C.: World Bank

World Bank, 2000b, Cities, Seas and Storms Managing Change in the Pacific Island Economies, Washington, D.C.: World Bank 